NOTA CIENTÍFICA

\title{
EFICIÊNCIA DA APLICAÇÃO EM PRÉ-COLHEITA DE CLOROTALONIL, TIOFANATO METÍLICO E TETRACONAZOLE NO CONTROLE DE PODRIDÃO PARDA EM PESSEGUEIRO
}

\section{EFFICIENCY OF PRE-HARVEST APPLICATION OF CLOROTALONIL, THIOPHANATE-METHYL AND TETRACONAZOLE ON PEACH BROWN ROT CONTROL}

\author{
Renato Rezende Young BLOOD ${ }^{1}$ \\ Luís Fernando ROVEDA ${ }^{2}$ \\ Louise Larissa MAY DE $\mathrm{MIO}^{3}$ \\ Luciene Martins MOREIRA ${ }^{4}$
}

\begin{abstract}
RESUMO
Pomares de pessegueiros são anualmente atacados pela podridão parda causada pelo fungo Monilinia fructicola causando perdas na produção. A redução do inóculo através de tratamento químico é uma das formas de controle. Sendo assim, este trabalho testou a eficiência da aplicação de fungicidas em pré-colheita, no controle de podridão parda na cultura do pessegueiro. O experimento foi realizado em pomar comercial no município de Lapa - PR, em blocos ao acaso, com oito

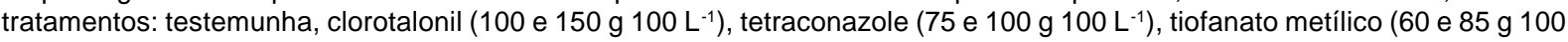

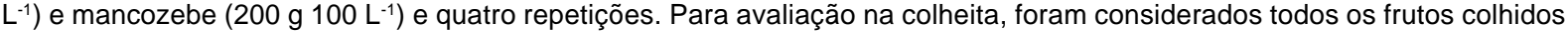
na região central de cada parcela, anotando-se o número total de frutos colhidos e o número de frutos com podridão parda em cada uma das três datas de colheita. Além disso, para cada data de colheita foram amostrados 10 frutos sadios, que foram acomodados em bandejas de alvéolos, mantidos à temperatura ambiente por 3 e 5 dias, avaliando-se a incidência da doença. O tiofanato metílico e o tetraconazole em ambas as dosagens e clorotalonil na maior dosagem foram os que exerceram o melhor controle da podridão parda a campo. Os produtos sistêmicos, tiofanato metílico e tetraconazole mostraram o maior efeito residual em pós-colheita.
\end{abstract}

Palavras-chave: pêssego; Monilinia fructicola; controle químico; pré-colheita.

\begin{abstract}
Peach orchards are affected annually by brown rot caused by the fungus Monilinia fructicola, leading to yield loss. The reduction of the inoculum by means of chemical treatment is one of the ways to control it. Thus, this work tested the efficiency of pre-harvest application of fungicides to control brown rot in peach crop. The experiment was conducted in a commercial orchard of Lapa - PR. The experimental design was randomized blocks, with eight treatments: check, clorotalonil

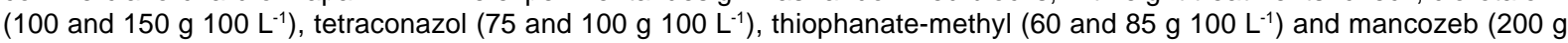
$\left.100 \mathrm{~L}^{-1}\right)$ and four replications. For the evaluation at harvest, all the fruits picked in the central region of each parcel were considered, and the total number of fruit picked and the number of fruit presenting brown rot in each of the harvest dates were also evaluated. Furthermore, for each harvest date samples of 10 healthy fruit were placed in alveolus trays, kept at room temperature for 3 and 5 days, and evaluated for disease incidence. Thiophanate-methyl and tetraconazole in both dosages and clorotalonil in the highest dosage were the most effective to control brown rot in the field. The systemic products, thiophanate-methyl and tetraconazole presented the highest post-harvest residual effect.
\end{abstract}

Key-words: peach; Monilinia fructicola; chemical control; pre-harvest.

\footnotetext{
1 Eng. Agrônomo, formado na UFPR. Rua Ulisses José Ribeiro, 360, casa 4; CEP 81530-590 Curitiba-Paraná- Brasil. renatoblood@yahoo.com.br. ${ }^{2}$ Mestrando do curso de Pós-graduação em Ciências do Solo do Departamento de Solo e Engenharia Agrícola da UFPR.

${ }^{3}$ Eng. Agr., Doutor em Fitopatologia, Professor do Departamento de Fitotecnia e Fitossanitarismo da UFPR, Rua dos Funcionários, 1540, 80035-050, Curitiba - PR, E-mail: maydemio@ufpr.br. Autor para correspondência

${ }^{4}$ Eng. Agr., Doutor em Produção Vegetal, professor da Unidade de Ensino Superior Vale do Iguaçu, Rua Padre Saporiti, 717, 84600-000, União da Vitória - PR. E-mail: Immoreira@terra.com.br.
} 


\section{INTRODUÇÃO}

O Estado do Paraná, segundo informações da Secretaria da Agricultura e do Abastecimento (SEAB), possui uma área de 1791,03 ha com a cultura do pessegueiro (Prunus persica), com uma produção de $17641,81 \mathrm{Mg}$ e produtividade média de $10 \mathrm{Mg} \mathrm{ha}^{-1}$ geralmente em pequenas propriedades, tendo função social por empregar um grande número de pessoas, mantendo o produtor na área rural. O principal produtor de pêssego na região de Curitiba é o município da Lapa, o qual foi responsável pela produção de $4725 \mathrm{Mg}$ em uma área de 350 ha na safra 2002/03, destacando-se entre todas as regiões produtoras do Estado.

A produtividade média brasileira está em 8 $\mathrm{Mg} \mathrm{ha}^{-1}$ ficando muito abaixo das obtidas em países como Itália, Estados Unidos, França que possuem média superior a $15 \mathrm{Mg} \mathrm{ha}^{-1}$ (FAO, 2003). A baixa produtividade, obtida no Brasil e Paraná, pode estar relacionada a aspectos climáticos, tratos culturais e práticas de manejo fitossanitário. Todavia, uma pequena parte dos produtores do estado obtém produtividades superiores a $30 \mathrm{Mg} \mathrm{ha}^{-1}$, isto é, quatro vezes a média nacional e paranaense.

O controle das doenças, juntamente com adubação, calagem e controle de pragas, é certamente um dos fatores que mais afetam a produtividade. Com relação às doenças, a de maior importância no Paraná é a podridão parda causada pelo fungo Monilinia fructicola que pode causar desde danos parciais a totais na produção de um pomar.

O fungo pode infectar as flores, ramos e frutos na pré e pós-colheita. Na infecção das flores pode haver necrose das anteras, ovário e pedúnculo, podendo matá-las. Estas se tornam marrons, murchas, podendo exibir esporulação do fungo e permanecerem fixas ao ramo por uma goma exsudada. A partir deste ponto, o fungo pode avançar penetrar no ramo e desenvolver cancros que podem anelá-lo causando murcha e morte da parte terminal, com intensa esporulação do fungo (WATSON et al., 2002; MAY-DE MIO et al., 2004). Nos frutos em amadurecimento, inicialmente, são observadas pequenas lesões pardas, com aspectos encharcados, que evoluem para extensas manchas marrons cobertas pela esporulação do fungo, principalmente quando estes se encontram na fase de maturação. Em seguida, os frutos começam a se desidratar tornando-se mumificados, permanecendo na planta ou no solo (MOREIRA, 2005).

Medidas de profilaxia são importantes para o controle da podridão parda, entre elas a poda de limpeza no inverno, com eliminação de ramos doentes, capulhos florais e frutos mumificados e os controles químicos, adotados em diferentes épocas, como inverno, e estádios da cultura, como na floração e pré-colheita (MAY-DE MIO et al., 2004). O controle químico em pré-colheita é indispensável para muitas áreas que ainda mantém inóculo alto (LUO et al., 2001) ou em casos de ocorrência de danos por insetos ou granizo na fase da frutificação. Outro fato a ser considerado no manejo é a necessidade de se fazer uma avaliação preliminar do inóculo no pomar visando uma correta aplicação dos produtos químicos (LUO et al., 2001).

Diante deste fato é essencial a busca por ingredientes ativos, bem como o acompanhamento da eficiência dos produtos que vem sendo utilizados no campo, e em situações especiais, buscar a liberação de produtos já disponíveis no mercado, que ainda não são liberados para utilização em alguns estados. Portanto, este trabalho teve por objetivo avaliar a eficiência de três ingredientes ativos de fungicidas (clorotalonil, tiofanato metílico e tetraconazole), que não se encontram liberados, para a cultura do pessegueiro, no estado do Paraná, em um pomar comercial no município de Lapa comparando-os com o fungicida mancozebe (liberado, no Paraná) e com parcelas sem controle da doença.

\section{METODOLOGIA}

\section{Experimento a campo}

O experimento foi instalado em pomar comercial de pessegueiro, em novembro de 2004 no município de Lapa no Paraná, localizado a uma altitude de $908 \mathrm{~m}$ acima do nível do mar situada na região sudeste do estado, no Planalto Meridional, com clima subtropical/Mesotérmico Brando.

A cultivar utilizada foi a BR-1, com plantas de cinco anos de idade espaçadas em $6 \mathrm{~m}$ nas entrelinhas e 1,5 m entre plantas, em sistema de condução em "Y", num total de 96 plantas, sendo 64 referentes à bordadura e 32 para coleta de dados. $O$ delineamento foi em blocos ao acaso com quatro repetições e oito tratamentos (Tabela 1), sendo cada parcela experimental composta de três plantas.

TABELA 1 - Produtos e dosagens utilizadas para o controle em pré-colheita da podridão parda do pessegueiro cultivar BR1, no município da Lapa - PR, 2005.

\begin{tabular}{lccc}
\hline Ingrediente Ativo & g i.a. 100 L & $\begin{array}{c}\text { Dosagem } \\
\text { (g ou mL 100 L }\end{array}$ & Formulação \\
\hline Tiofanato metilico & 51,00 & 60 & Concentrado emulsionável \\
Tiofanato metilico & 72,25 & 85 & Concentrado emulsionável \\
Chlorothalonil & 85,00 & 100 & Pó molhável \\
Chlorothalonil & 127,50 & 150 & Pó molhável \\
Tetraconazole & 7,50 & 75 & Concentrado emulsionável \\
Tetraconazole & 10,00 & 100 & Concentrado emulsionável \\
Mancozebe & 160,00 & 200 & Pó molhável \\
\hline
\end{tabular}


Foram feitas duas pulverizações em précolheita, com 7 dias de intervalo, permitindo-se um espaço de 10 dias sem aplicação antes do início da colheita. Estas foram realizadas no período da manhã, com pulverizadores costais de $16 \mathrm{~L}$ com bico cônico vazio padrão Jacto e vazão de $0,75 \mathrm{~L}$ $\mathrm{min}^{-1}$, sendo realizada uma pulverização homogênea em toda a planta. Os demais tratos culturais como adubação e aplicação de inseticidas foram realizados conforme o manejo adotado pela propriedade.

\section{Avaliações da podridão parda na colheita e pós- colheita}

A avaliação foi feita pela incidência, considerando-se número de frutos com podridão parda e total de frutos colhidos por árvore e por colheita, em cada parcela, conforme recomendado por MAY-DE MIO et al. (2004). Foram realizadas três colheitas durante o experimento, no $10^{\circ}, 13^{\circ}$ e $16^{\circ}$ dias após a última pulverização.

Nos três dias de colheita, os frutos foram pesados e contados a campo, obtendo-se o total de frutos e o número de frutos infectados por $M$. fructicola. Em cada colheita foram coletados 10 frutos por parcela, sem infecção aparente, e estes foram transportados ao Laboratório de Fitopatologia da UFPR para avaliação da podridão parda em póscolheita. Os frutos foram acomodados em bandejas com alvéolos, à temperatura ambiente, e avaliados aos cinco dias após a colheita pela incidência da doença.

A análise estatística foi executada com programa SASM-Agri versão 8.0 (CANTERI et al., 2001), utilizando-se ANOVA e o teste de Scott-Knott a $5 \%$, método de agrupamento usado como alternativa em que procedimentos de comparações múltiplas são recomendados, com a característica de não apresentar ambigüidade nos resultados.

\section{RESULTADOS E DISCUSSÃO}

\section{Avaliação da podridão parda na colheita}

Os dados para porcentagem de podridão parda do pessegueiro na colheita estão apresentados na Tabela 2. Observou-se que no $10^{\circ}$ e $13^{\circ}$ dias após a última aplicação não houve diferença significativa entre os tratamentos. Entre estes dois dias de avaliação, houve um discreto aumento do percentual de podridão parda nos tratamentos tiofanato metílico (51 g $\left.100 \mathrm{~L} \mathrm{~L}^{-1}\right)$, clorotalonil (85 g $\left.100 \mathrm{~L}^{-1}\right)$ e tetraconazole $(10 \mathrm{~g} 100$ $\left.\mathrm{L}^{-1}\right)$. Já para os tratamentos clorotalonil (127,5 g 100

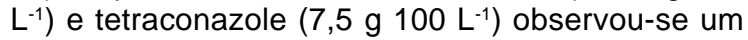
aumento acima de $10 \%$ na incidência (Tabela 2). Neste mesmo período, o tiofanato metílico $(72,25 \mathrm{~g}$ $100 \mathrm{~L}^{-1}$ ) e o mancozebe foram os mais eficientes no controle da doença, enquanto a testemunha apresentou $23,7 \%$ de incidência (Tabela 2). Do $13^{\circ}$ para $016^{\circ}$ dia a incidência aumentou em todos os tratamentos, o que pode ser devido ao efeito residual dos produtos já estar menor e o inóculo do patógeno começar a aumentar nesta fase do ciclo da cultura. Constatou-se, ainda, no $16^{\circ}$ dia, uma diferença no residual entre produtos sistêmicos e de contato, observando-se que plantas tratadas com mancozebe e clorotalonil (85 g $\left.100 \mathrm{~L}^{-1}\right)$ apresentaram frutos com alta incidência da doença, enquanto tiofanato metílico, tetraconazole e clorotalonil $\left(127,5 \mathrm{~g} 100 \mathrm{~L}^{-1}\right)$ diferiram da testemunha, que teve $62,4 \%$ de frutos doentes.

TABELA 2 - Incidência, em porcentagem, da podridão parda do pessegueiro cultivar BR1, avaliada na colheita e pós-colheita, sob diferentes tratamentos com fungicidas, Lapa - PR, 2005.

\begin{tabular}{|c|c|c|c|c|c|c|}
\hline \multirow{3}{*}{ Tratamentos } & \multirow{2}{*}{\multicolumn{3}{|c|}{$\begin{array}{c}\begin{array}{c}\% \text { frutos com podridão parda na } \\
\text { colheita }\end{array} \\
\text { Dias após a última aplicação }\end{array}$}} & \multirow{2}{*}{\multicolumn{3}{|c|}{$\begin{array}{c}\text { Porcentagem de frutos com podridão } \\
\text { parda na pós -colheita }\end{array}$}} \\
\hline & & & & & & \\
\hline & $10^{1,2}$ & $13^{1,2}$ & $16^{1}$ & $10^{1,2}$ & $13^{1,2}$ & $16^{1}$ \\
\hline Testemunha & $24,6 n s$ & $23,7 n s$ & $62,4 \mathrm{a}$ & $80 a$ & $68 \mathrm{~ns}$ & $98 a$ \\
\hline Tiofanato Metílico (51) & 17,0 & 17,8 & $35,7 \mathrm{~b}$ & $48 \mathrm{~b}$ & 45 & $95 \mathrm{a}$ \\
\hline Tiofanato Metílico $(72,25)$ & 12,4 & 8,6 & $29,6 b$ & $50 \mathrm{~b}$ & 31 & $100 \mathrm{a}$ \\
\hline Clorotalonil (85) & 22,0 & 20,8 & $70,1 \mathrm{a}$ & $80 a$ & 65 & $100 \mathrm{a}$ \\
\hline Clorotalonil $(127,5)$ & 8,5 & 20,1 & $41,5 b$ & $68 a$ & 45 & $80 \mathrm{~b}$ \\
\hline Tetraconazole $(7,5)$ & 8,4 & 21,6 & $46,4 \mathrm{~b}$ & $43 \mathrm{~b}$ & 24 & $85 b$ \\
\hline Tetraconazole (10) & 3,1 & 5,1 & $24,8 \mathrm{~b}$ & $48 \mathrm{~b}$ & 30 & $98 \mathrm{a}$ \\
\hline Mancozebe (160) & 21,8 & 7,7 & $57,6 \mathrm{a}$ & $70 \mathrm{a}$ & 45 & $98 \mathrm{a}$ \\
\hline $\mathrm{CV}$ & 68,81 & 59,8 & $27,74^{\star \star}$ & $21,5^{*}$ & 32,4 & $8,80^{*}$ \\
\hline
\end{tabular}

O ingrediente ativo clorotalonil $(127,5 \mathrm{~g} 100$ $\left.\mathrm{L}^{-1}\right)$, no $10^{\circ}$ dia, apresentou-se eficiente, no entanto, no $13^{\circ}$ dia a incidência aumentou, sendo que tiofanato metílico $\left(72,25 \mathrm{~g} .00 \mathrm{~L}^{-1}\right)$ e tetraconazole

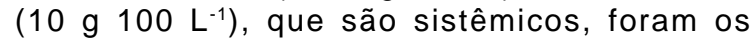
melhores (Tabela 2). O clorotalonil foi eficaz no controle da podridão parda em pessegueiro, quando utilizado no México, obtendo-se $93 \%$ de eficiência (ESTRADA et al., 1992). Além disso, FORTES (1994) também obteve controle de $M$. fructicola com aplicações de clorotalonil e de mancozebe, durante a pré-colheita, em pomar de pessegueiro no Rio Grande do Sul. NOGUEIRA (1993) avaliou, em São Paulo, os fungicidas tebuconazole, clorotalonil e mancozebe em diferentes dosagens e estádios da cultura do pessegueiro, obtendo controle da podridão parda. De modo semelhante, DE VICENZO et al. (1997) e WADT et al. (1999), concluíram que o fungicida tebuconazole, mesmo grupo do tetraconazole, foi altamente eficiente no controle da podridão parda em pessegueiro e nectarineira, respectivamente. 
Foi observado na Tabela 2, que a análise estatística para frutos com podridão parda na colheita, no $10^{\circ}$ e $13^{\circ}$ após a última aplicação, gerou coeficientes de variação elevados, o que não aconteceu no $16^{\circ}$ dia. Este fato pode ser explicado pela variação no número de frutos colhidos em cada colheita, sendo nas duas primeiras colhidos 945 e 552 frutos, respectivamente e na última (pico de colheita), 2434 frutos. Sendo assim, o baixo número de frutos nas primeiras colheitas ocasionou um elevado coeficiente de variação para os $10^{\circ}$ e $13^{\circ}$ dias.

A eficiência do ingrediente ativo tetraconazole indica a possibilidade de seu uso dentro de um sistema de manejo, como nova ferramenta por ser de grupo químico diferente dos registrados para controle da doença. Entretanto, deve ser considerado o número de aplicações por ciclo, visando impedir a seleção de raças resistentes do patógeno.

\section{Avaliação da podridão parda na pós-colheita}

$\mathrm{Na}$ avaliação em pós-colheita (10ำ dia), os produtos sistêmicos tiofanato metílico e tetraconazole foram os mais eficientes no controle da podridão parda (Tabela 2). Aos 13 dias após a última aplicação pôde-se observar uma incidência menor em todos os tratamentos, comparando-se a avaliação anterior. Um fator importante que pode influenciar esta flutuação é a maior presença de infecções latentes nos frutos da primeira colheita.

As infecções latentes vêm de flores que sobrevivem à infecção pelo fungo originando frutos contendo o patógeno (MOREIRA e MAY-DE MIO, 2007). Conforme citada anteriormente, a segunda colheita, da qual foram provenientes os frutos para esta análise, forneceu menor número de frutos (552 no total) e nesta amostragem o número com infecções latentes foi inferior, indicando que houve um controle eficiente na fase de floração. Por isso, para um maior esclarecimento é viável que um próximo experimento envolva a análise da podridão parda na floração, para se correlacionar a doença nesta fase com a pós-colheita.

No $16^{\circ}$ dia a avaliação mostrou uma incidência elevada nos frutos avaliados. Apenas os tratamentos clorotalonil $\left(127,5 \mathrm{~g}_{\left.100 \mathrm{~L}^{-1}\right)} \mathrm{e}\right.$

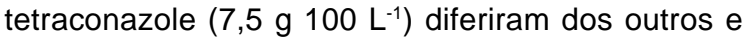
da testemunha (Tabela 2). Em concordância, WADT et al. (1999) observaram na pós-colheita que o tratamento composto por triazóis foi o mais eficiente, ao passo que o uso do clorotalonil não controlou a doença. No período referente a esta última avaliação deu-se o pico de colheita, que coincide com as condições climáticas ideais ao patógeno, facilitando sua expressão na pós-colheita.

\section{CONCLUSÕES}

Os produtos tiofanato metílico, tetraconazole e também o clorotalonil, na maior dosagem, proporcionaram controle da doença na colheita e mostraram também efeito residual. Nenhum tratamento apresentou fitotoxicidade ao pessegueiro nas dosagens testadas.

\section{REFERÊNCIAS}

1. CANTERI, M.G., ALTHAUS, R.A., VIRGENS FILHO, J.S., GIGLIOTI, E.A.; GODOY, C.V. SASM-Agri: Sistema para análise e separação de médias em experimentos agrícolas pelos métodos Scott-Knott, Tukey e Duncan. Revista Brasileira de Agrocomputação, v. 1, n. 2, p. 18-24, 2001.

2. DE VICENZO, M.C.V.; VEIGA, J.S.; DARIO, G.J.A. Controle da podridão parda (Monilinia fructicola) na cultura do pêssego (Prunus persica) com o fungicida tebuconazole. Horticultura Brasileira, v. 15, supl., res. 88, 1997.

3. ESTRADA, H.F.; ZAMORA, C.M.; GONZÁLEZ, F.P. Control químico de la cenicilla (Sphaerotheca pannosa (Wallr.) Lev. Var. persicae Wor.) y pudricion morena (Monilinia fructicola (Wint.) Honey) em Buena Vista Mich., México. Chapingo, n. 78, p. 100-103, 1992.

4. FAO. Statistical Database. Disponível em <http://apps.fao.org/default.htm>. Acesso em: 08 jul. 2003.

5. FORTES, J.F. Controle de Monilinia fructicola em Prunus persica na pré-colheita. Fitopatologia Brasileira, v. 19, supl., p. 327, 1994.

6. LUO, Y.; MORGAN, D. P.; MICHAILIDES, T. J. Risk analysis of brown rot blossom blight of prune caused by Monilinia fructicola. Phytopathology, v. 9, p 759-768, 2001.

7. MAY DE MIO, L.L.; GARRIDO, L.; UENO, B. Doenças de fruteira de caroço. In: MONTEIRO, L.B.; MAY DE MIO, L.L.; MONTE SERRAT, B.; MOTTA, A.C.V. CUQUEL, F.L. Fruteira de caroço: uma visão ecológica. Curitiba, 2004. p. 333-362.

8. MOREIRA, L.M. Alternativas de controle integrado da podridão parda do pessegueiro. Curitiba, $2005.113 \mathrm{f}$. Tese (Doutorado em Produção Vegetal) - Universidade Federal do Paraná, Setor de Ciências Agrárias, Programa de PósGraduação em Produção Vegetal.

9. MOREIRA, L. M.; MAY DE MIO, L.L. Metodologia para detecção de infecções latentes de Monilinia fructicola em frutas de caroço. Ciência Rural, v. 37, n. 3, p. 628-633. 2007.

10. NOGUEIRA, E.M. de C. Controle químico da podridão parda (Monilinia fructicola) em pessegueiro (Prunus persica). Summa Phytopathologica, v. 19, n. 1, p. 48, 1993. Resumo.

11. WADT, L.; NOGUEIRA, E.M. de C.; CORRENTE, J.E. Controle químico da podridão parda (Monilinia fructicola) em nectarina (Prunus persica var. nucipersica). Arquivos do Instituto Biológico, v. 66, n. 1, p. 9-14, 1999.

12. WATSON, W.A.; ZEHR, E.I.; GRIMES, L.W. Influence of temperature and wetting period on inoculum production by Monilinia fructicola in peach twig cankers. Plant Disease, v. 86, n. 6, p. 666-668. 2002.

Recebido em 23/05/2007

Aceito em 18/10/2007 